Article

\title{
Effects of Exposed Artificial Substrate on the Competition between Phytoplankton and Benthic Algae: Implications for Shallow Lake Restoration
}

\author{
Hu He ${ }^{1, *}$, Xuguang Luo ${ }^{2}$, Hui Jin ${ }^{3}$, Jiao Gu ${ }^{1,4}$, Erik Jeppesen ${ }^{5,6}$, Zhengwen Liu ${ }^{1,6,7}$ and \\ Kuanyi Li ${ }^{1,6, *}$ \\ 1 State Key Laboratory of Lake Science and Environment, Nanjing Institute of Geography and Limnology, \\ Chinese Academy of Sciences, Nanjing 210008, China; jiao.g@yahoo.com (J.G.); zliu@niglas.ac.cn (Z.L.) \\ 2 College of Animal Science, Inner Mongolia Agricultural University, Huhhot 010018, China; \\ luoxuguang899@163.com \\ 3 School of Environmental and Civil Engineering, Jiangnan University, Wuxi 214122, China; jinhuihj@163.com \\ 4 University of Chinese Academy of Sciences, Beijing 100049, China \\ 5 Department of Bioscience, Aarhus University, 8600 Aarhus, Denmark; ej@bios.au.dk \\ 6 Sino-Danish Centre for Education and Research, Beijing 100049, China \\ 7 Department of Ecology and Institute of Hydrobiology, Jinan University, Guangzhou 510632, China \\ * Correspondence: hehu@niglas.ac.cn (H.H.); kyli@niglas.ac.cn (K.L.); \\ Tel.: +86-25-8688-2237 (H.H.); +86-25-8688-2179 (K.L.)
}

Academic Editor: Miklas Scholz

Received: 24 October 2016; Accepted: 30 December 2016; Published: 4 January 2017

\begin{abstract}
Phytoplankton and benthic algae coexist in shallow lakes and the outcome of the competition between these two photoautotrophs can markedly influence water clarity. It is well established that exposed artificial substrate in eutrophic waters can remove nutrients and fine particles from the water column via the attached periphyton canopy. However, the effects of the introduction of artificial substrate on the competition between planktonic and benthic primary producers remain to be elucidated. We conducted a short-term outdoor mesocosm experiment to test the hypothesis that the nutrient and light changes induced by exposed artificial substrate (polythene nets) would benefit the benthic algae. Artificial substrate significantly reduced total nitrogen and phosphorus concentrations and water clarity improved, the latter due to the substrate-induced reduction of both organic and inorganic suspended solids. Consequently, as judged from changes in chlorophyll $a$ (Chl-a) concentrations in water and sediment, respectively, exposed artificial substrate significantly reduced the phytoplankton biomass, while benthic algae biomass increased. Our results thus indicate that exposed artificial substrate may be used as a tool to re-establish benthic primary production in eutrophic shallow lakes after an external nutrient loading reduction, paving the way for a benthic- or a macrophyte-dominated system. Longer term and larger scale experiments are, however, needed before any firm conclusions can be drawn on this.
\end{abstract}

Keywords: artificial substrate; phytoplankton; benthic algae; resource competition; shallow lakes

\section{Introduction}

Shallow lakes may exist in one of two alternative states-a clear state with an abundant community of submerged macrophytes and a turbid state characterized by high phytoplankton biomass [1]. However, in shallow clear water lakes where submerged macrophytes are absent, benthic algae (epipelon) may dominate primary production and help to maintain a clear water state [2-4].

Light and nutrients are fundamental factors impacting the relative contribution of planktonic and benthic algae to total primary production in shallow lakes [5-8]. Excessive nutrient loading often 
boosts the growth of phytoplankton, resulting in reduced light penetration and, with it, decreases in benthic algae biomass [2,9]. Moreover, loss of benthic algae promotes phytoplankton growth through reduced competition for nutrients and enhanced nutrient release from the sediment [10]. Contrarily, benthic algae often benefit from the enhanced water clarity and decrease the availability of nutrients for phytoplankton in the overlying water by consuming the resources that these require for growth and indirectly also by immobilizing nutrients within sediments [10].

Despite a large reduction of the external nutrient loading for the purpose of restoration of shallow eutrophic lakes, benthic primary producers may take time to recover due to competition by excessively growing planktonic algae [11], caused by high internal loading and an unfavorable food web structure $[12,13]$. The introduction of exposed artificial substrate may promote the production of benthic algae competing with phytoplankton due to changes in nutrient and light conditions through periphyton colonization on the surface of the artificial substrate (hereafter referred to as 'periphyton'). Firstly, periphyton assemblages can remove nutrients, especially phosphorus, from the water column [14-17], which may competitively reduce phytoplankton growth $[6,8,18]$. For instance, Jöbgen et al. (2004) studied the potential of periphyton for phosphorus removal on polypropylene (PP) fleece in Lake Fühlinger in Cologne, Germany, and found that up to ca. $100 \mathrm{mg}$ total phosphorus was bound per $\mathrm{m}^{2}$ PP-fleece after four months of exposure [19]. Secondly, the periphyton canopy has the potential of retaining suspended solids in the water column via changes in flow hydraulics or direct particle trapping and adhesion [20-23]. For instance, Battin et al. (2003) showed that some forms of photosynthetically active periphyton produce a 'sticky' exopolysaccharide (EPS) matrix that has been shown to enhance particle deposition [21]. Benthic algae may therefore benefit from enhanced light penetration via the removal of suspended particles. To date, the effects of exposed artificial substrate on nutrient removal and/or particle retention in lakes and rivers are well studied [16,17,19-22], whereas the impact of the introduction of artificial substrate on the competition between pelagic and benthic primary production remains to be elucidated.

In this study, outdoor mesocosms were used to explore the effects of periphyton on the competition between planktonic and benthic algae in eutrophic waters mediated by the introduction of artificial substrate. We hypothesized that periphyton would reduce nutrient concentrations and enhance water clarity. The changes in nutrient and light conditions would reduce phytoplankton growth, whereas the growth of benthic algae would be favored due to the improved light climate.

\section{Materials and Methods}

The outdoor mesocosm experiment was conducted at the Taihu Lake Laboratory Ecosystem Research Station (TLLER), which is located in Meiliang Bay, the northern part of Lake Taihu, China (Figure 1). Lake Taihu is a large (surface area: $2338 \mathrm{~km}^{2}$ ), shallow (mean depth: $2 \mathrm{~m}$ ), and hypertrophic freshwater lake which has suffered severe cyanobacterial blooms (dominated by Microcystis spp.) in the last two decades [24]. Our experiment was conducted from 5 October 2014 to 11 November 2014. According to the meteorological data obtained from TLLER, average water temperature in both months was $15^{\circ} \mathrm{C}$ (Range: $12-20{ }^{\circ} \mathrm{C}$ ). Average wind speed at the site was measured twice, being $2.9 \mathrm{~m} / \mathrm{s}$ on 14 October and $0.15 \mathrm{~m} / \mathrm{s}$ on 15 November.

\subsection{Experimental Design}

Eight cylindrical, high-density polyethylene tanks (depth: $60 \mathrm{~cm}$; upper diameter: $50 \mathrm{~cm}$; bottom diameter: $40 \mathrm{~cm}$ ) were placed on the lake shore. Each tank was filled with a $5 \mathrm{~cm}$ layer of sediment and $70 \mathrm{~L}$ water collected from Meiliang Bay. The sediments had previously been sieved (mesh size: $1.7 \mathrm{~mm}$ ) to remove large invertebrates and mixed to ensure uniformity. The water was screened using a $64 \mu \mathrm{m}$ mesh filter to remove crustacean zooplankton and inorganic particles. 


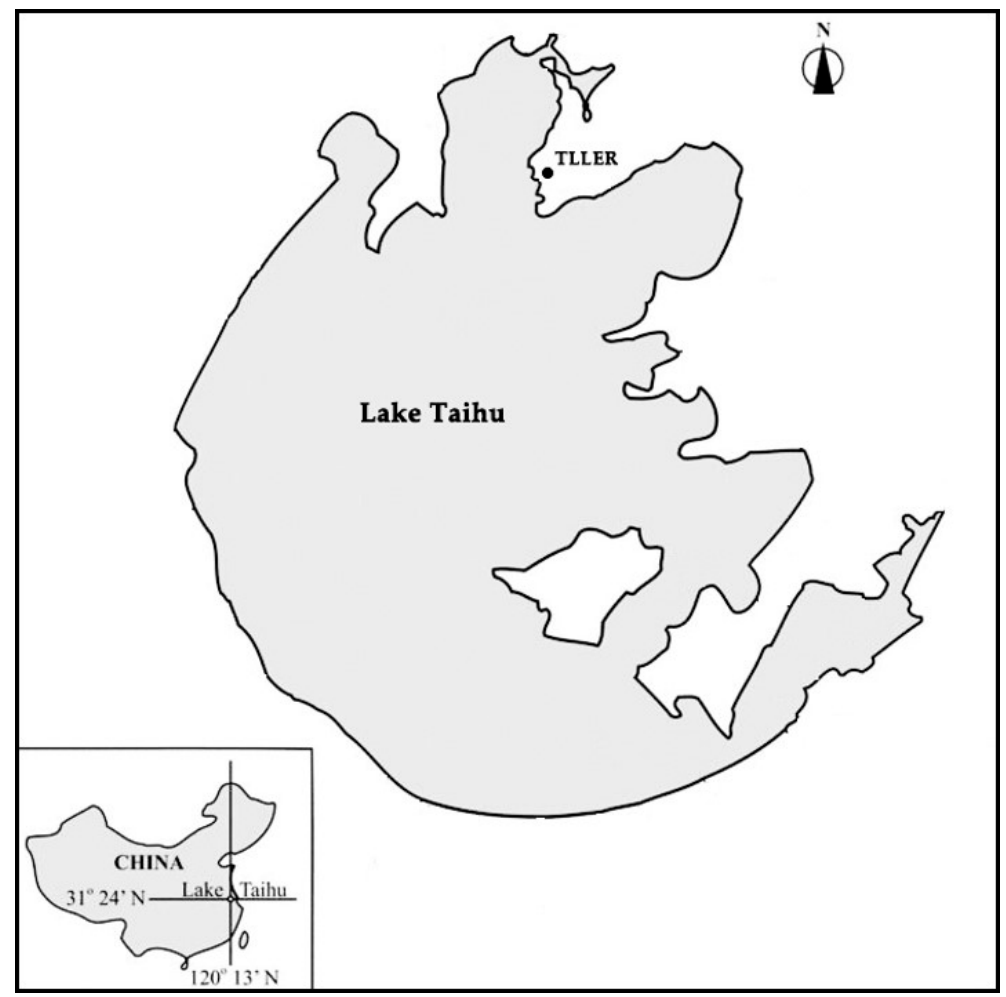

Figure 1. Location of Lake Taihu in China (the solid dot shows Taihu Lake Laboratory Ecosystem Research Station (TLLER) where the mesocosm experiment was conducted).

The artificial substrates used in the experiment were cylindrical-shaped $(40 \mathrm{~cm}$ height $\times 30 \mathrm{~cm}$ diameter) polythene nets with a mesh size of $3 \mathrm{~mm}$. We chose this material not only because it was a substratum well suited for periphyton settlement [25], but also because it does not affect nutrient diffusing as do conventionally used artificial substrates, such as plastic sheets or glass slides. To initiate the experiment, artificial substrate was randomly added to four mesocosms. Each tank contained one net with a total surface area of $0.75 \mathrm{~m}^{2}$ (each $\mathrm{m}^{2}$ of the polythene net exposes $2 \mathrm{~m}^{2}$ surface area). The artificial substrates extended through the entire water column and were vertically fixed in the sediment. The remaining four mesocosms without artificial substrate functioned as controls.

\subsection{Sampling and Analytical Methods}

In the morning of day 0 ( 5 October) $, 4,8,12,16,20,28$, and 36 of the experiment, in situ turbidity was measured in each mesocosm at $20 \mathrm{~cm}$ water depth using a YSI 9500 Photometer (YSI, Inc., Yellow Springs, OH, USA). After that, a small (1 L) depth-integrated water sample was collected from each mesocosm using a tube sampler $(8 \mathrm{~cm}$ diameter, $64 \mathrm{~cm}$ length). The water samples were then analyzed in the laboratory for nutrients, suspended solids, and chlorophyll $a$ (Chl- $a$ ).

Total suspended solids (TSS) were determined from 200 to $400 \mathrm{~mL}$ water samples filtered through pre-weighed glass fiber filters (GF/C, Whatman International Ltd., Maidstone, UK), which had been pre-combusted at $450{ }^{\circ} \mathrm{C}$ for $2 \mathrm{~h}$. The filters were then dried to a constant weight at $60{ }^{\circ} \mathrm{C}$ for $48 \mathrm{~h}$. After determining TSS, the filters were combusted in a muffle furnace at $550{ }^{\circ} \mathrm{C}$ for $2 \mathrm{~h}$, then cooled in a desiccator, and finally weighed to determine the inorganic suspended solid (ISS) concentration. We calculated the organic fraction (OSS) by subtracting ISS from TSS. Total nitrogen (TN), total phosphorus (TP), total dissolved nitrogen (TDN), and total dissolved phosphorus (TDP) concentrations were measured according to Chinese standard methods [26]. The Chl- $a$ concentration was measured spectrophotometrically from the matter retained on a GF/C filter after extraction in a $90 \%(v / v)$ acetone/water solution for $24 \mathrm{~h} \mathrm{[27].} \mathrm{We} \mathrm{did} \mathrm{not} \mathrm{correct} \mathrm{for} \mathrm{phaeophytin} \mathrm{interference.}$ 
At the end of the experiment (day 36), after the ordinary water sampling, periphyton on the artificial substrate and benthic algae were sampled in each mesocosm. For periphyton, each artificial substratum was carefully removed, and a vertical $5 \mathrm{~cm}$ wide and $35 \mathrm{~cm}$ deep strip (from top to sediment surface area) was cut from each substratum and immediately enclosed in a black zip-lock bag. In the laboratory, the attachments on both sides of the strip were carefully brushed off into a beaker with distilled water, mixed thoroughly, and divided equally into two subsamples. One subsample (100-200 mL) was filtered through pre-weighed, pre-combusted $\left(4 \mathrm{~h}\right.$ at $\left.450{ }^{\circ} \mathrm{C}\right) \mathrm{GF} / \mathrm{C}$ filter and dried at $105{ }^{\circ} \mathrm{C}$ for $2 \mathrm{~h}$ in order to determine periphyton dry weight, and the other subsample was used to determine the periphyton Chl- $a$ concentration of the attachments using the method of water Chl- $a$ measurement. For benthic algae sampling, sediments in the center of each mesocosm were sampled in a small transparent tube (diameter: $2 \mathrm{~cm}$ ). The upper $0-1 \mathrm{~cm}$ sediments were collected and subsequently filtered through a GF/C filter. The Chl- $a$ concentration of benthic algae was also determined by spectrophotometry without correction for phaeophytin interference, as described above.

At the end of the experiment, the total biomasses of phytoplankton and benthic algae in each mesocosm were calculated. Total phytoplankton biomass was obtained by multiplying the water Chl- $a$ concentration by the volume of the water column, total benthic algal biomass by multiplying the Chl- $a$ concentration of benthic algae by the surface area of the sediment, and total algae biomass by summing up the total phytoplankton biomass and the total benthic algae biomass. The relative proportions of phytoplankton and benthic algae to the total algal biomass were then calculated.

Repeated measures analysis of variance (rANOVA) was applied to compare the differences $(p<0.05)$ in nutrients, suspended solids, and Chl- $a$ concentrations between the mesocosms with and without artificial substrate. Benthic algae were only sampled once. Subsequently, differences in benthic algae Chl- $a$ concentrations between the treatments were compared using Student's $t$-test $(p<0.05)$. When necessary, data were $\log 10$ transformed to ensure normality of distribution and homogeneity of variance before analysis. All statistical analyses were performed with the statistical package SPSS version 16.0 (IBM Corporation, Somers, NY, USA).

\section{Results}

\subsection{Nutrients and Turbidity}

In mesocosms with artificial substrate, periphyton dry weight and Chl- $a$ concentration were $1.53 \mathrm{mg} / \mathrm{cm}^{2}$ and $0.97 \mu \mathrm{g} / \mathrm{cm}^{2}$, respectively. The concentrations of TN and TP were both significantly lower in the mesocosms with artificial substrate than in the substrate-free controls (Table 1; Figure 2a,b), whereas no significant differences were found in dissolved nutrients (TDN and TDP) (Table 1; Figure $2 \mathrm{c}, \mathrm{d})$.

Table 1. Results of Analysis of Variance for repeated measures (rANOVA) for turbidity, suspended solids, nutrients, and Chl- $a$ of phytoplankton between treatments with and without artificial substrate.

\begin{tabular}{cccccccccc}
\hline & \multicolumn{3}{c}{ Artificial Substrate } & \multicolumn{3}{c}{ Time } & \multicolumn{3}{c}{ Interaction } \\
\cline { 2 - 10 } & F & DF & $p$ & F & DF & $\boldsymbol{p}$ & F & DF & $p$ \\
\hline TN & 121.86 & 1 & $<0.001$ & 299.75 & 7 & $<0.001$ & 13.44 & 7 & $<0.001$ \\
TP & 41.57 & 1 & 0.003 & 118.95 & 7 & $<0.001$ & 13.71 & 7 & $<0.001$ \\
TDN & 11.43 & 1 & 0.015 & 282.03 & 7 & $<0.001$ & 1.15 & 7 & 0.352 \\
TDP & 11.47 & 1 & 0.028 & 96.71 & 7 & $<0.001$ & 9.47 & 7 & 0.006 \\
Turb & 13.26 & 1 & 0.011 & 29.38 & 7 & $<0.001$ & 4.12 & 7 & 0.044 \\
TSS & 30.12 & 1 & 0.002 & 22.77 & 7 & $<0.001$ & 6.89 & 7 & 0.012 \\
OSS & 61.19 & 1 & $<0.001$ & 20.18 & 7 & $<0.001$ & 8.59 & 7 & $<0.001$ \\
ISS & 7.71 & 1 & 0.038 & 24.13 & 7 & $<0.001$ & 2.77 & 7 & 0.095 \\
Chl- $a$ & 39.18 & 1 & 0.001 & 50.74 & 7 & $<0.001$ & 8.32 & 7 & 0.002 \\
\hline
\end{tabular}

Notes: $\mathrm{TN}=$ total nitrogen; TP = total phosphorus; TDN = total dissolved nitrogen; TDP = total dissolved phosphorus; Turb = turbidity; TSS = total suspended solids; ISS = inorganic suspended solids; OSS = organic suspended solids; $\mathrm{Chl}-a=$ chlorophyll $a$ of phytoplankton; $\mathrm{F}=\mathrm{F}$ value; $\mathrm{DF}=$ degree of freedom; $p=p$ value. 

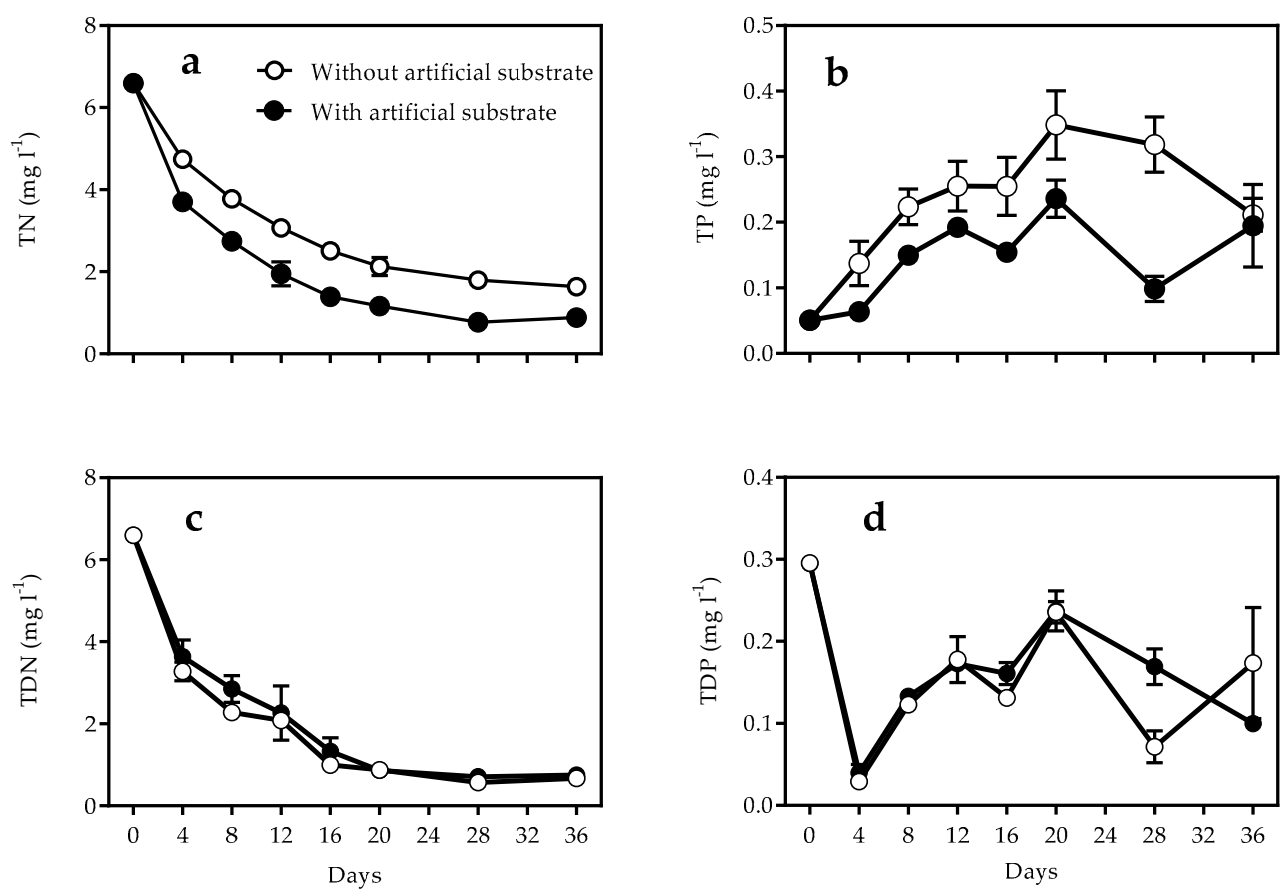

Figure 2. Comparisons of concentrations of (a) total nitrogen (TN); (b) total phosphorus (TP); (c) total dissolved nitrogen (TDN); and (d) total dissolved phosphorus (TDP) between treatments with and without artificial substrate during the experiment.

Artificial substrate significantly reduced the turbidity in the water column, turbidity being twice as high in the controls as in the artificial substrate mesocosms at the end of the experiment (Table 1; Figure 3a). Periphyton on artificial substrate also significantly reduced the concentrations of suspended solids, TSS (Figure 3b), OSS (Figure 3c), and ISS (Figure 3d) (Table 1).
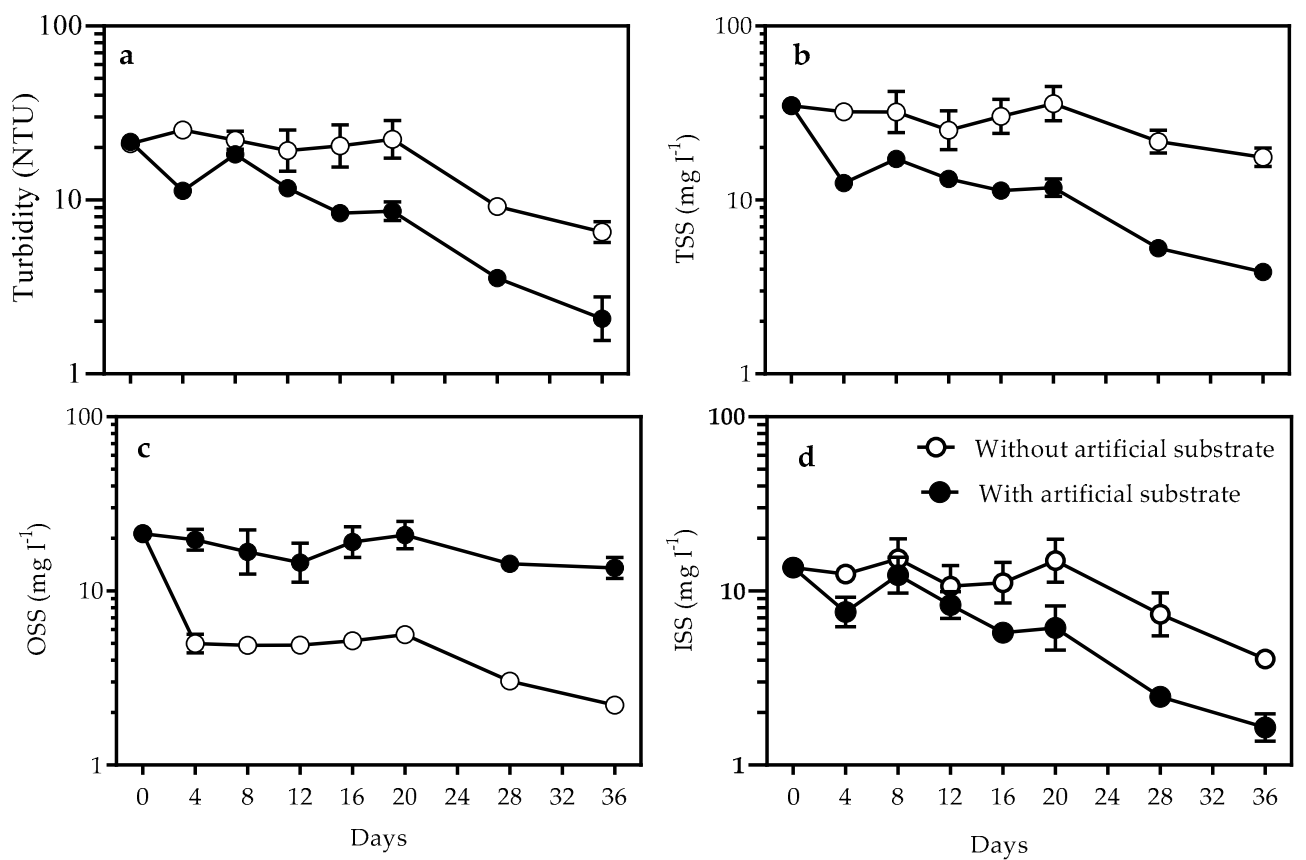

Figure 3. Comparisons of (a) turbidity; (b) total suspended solids (TSS); (c) organic suspended solids (OSS); and (d) inorganic suspended solids (ISS) concentrations between treatments with and without artificial substrate during the experiment. 


\subsection{Biomass of Phytoplankton and Benthic Algae}

Addition of artificial substrate significantly reduced the phytoplankton biomass, with water Chl- $a$ concentrations being significantly lower in the artificial substrate mesocosms than in the control mesocosms (Table 1; Figure 4a). For instance, at the end of the experiment, water Chl- $a$ concentrations were five times higher $(30.57 \pm 8.62 \mu \mathrm{g} / \mathrm{L})$ in the control treatment than in the artificial substrate treatment $(5.15 \pm 0.62 \mu \mathrm{g} / \mathrm{L})$ (Figure $4 \mathrm{a})$. In contrast, the Chl- $a$ concentrations of benthic algae were significantly lower in the control mesocosms $\left(1.23 \pm 0.11 \mu \mathrm{g} / \mathrm{cm}^{2}\right)$ than in the mesocosms with artificial substrate $\left(4.00 \pm 0.37 \mu \mathrm{g} / \mathrm{cm}^{2}\right)$ ( $t$-test, $\mathrm{F}(1,5)=79.00 ; p=0.001$; Figure $\left.4 \mathrm{~b}\right)$.
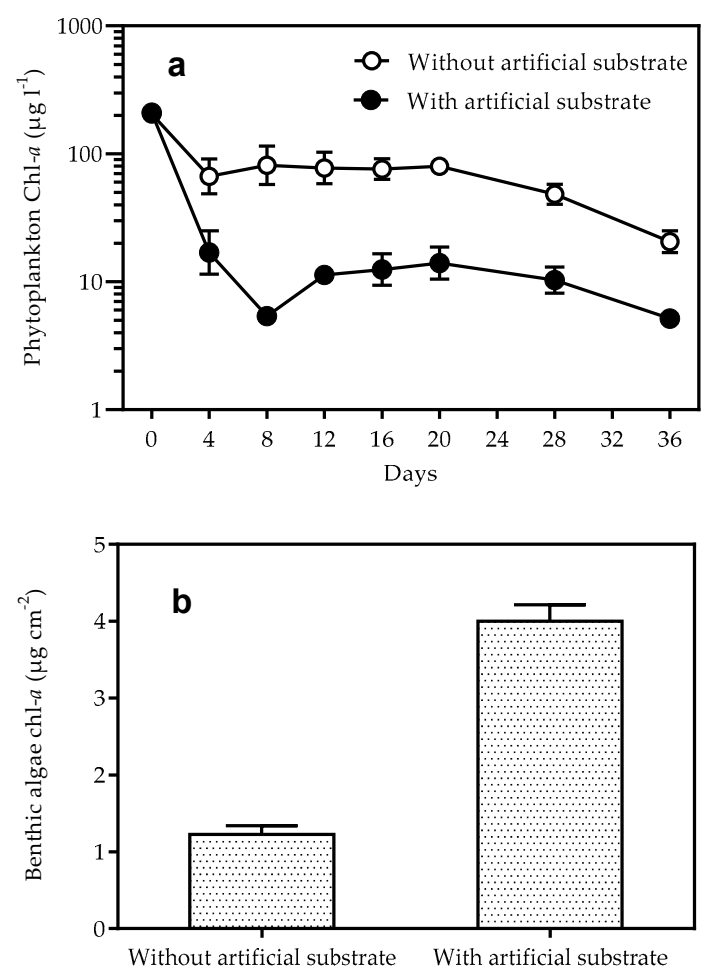

Figure 4. Comparison of chlorophyll $a(\mathrm{Chl}-a)$ concentrations of (a) phytoplankton; and (b) benthic algae at the end of experiment with and without artificial substrate.

In addition to the changes in overall abundance, the relative proportions of phytoplankton and benthic algae of total algal biomass varied between treatments (Figure 5). Artificial substrate significantly increased the proportions of benthic algae (from $46.6 \%$ to $93.3 \%$ ) (Figure 5).

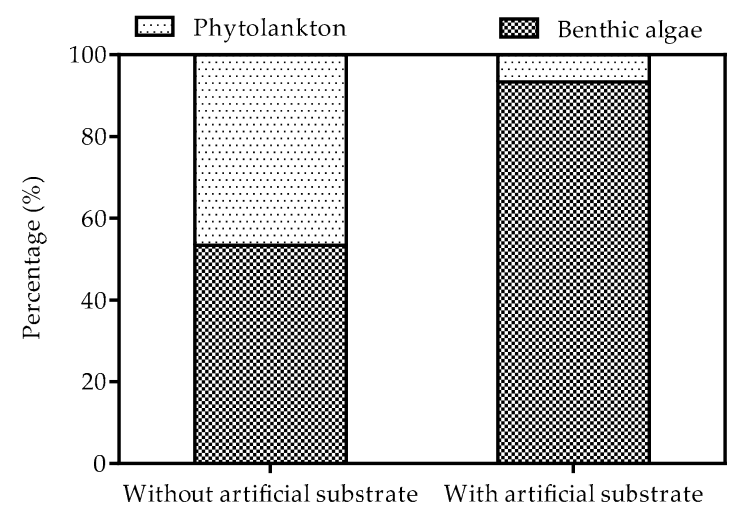

Figure 5. Contribution of phytoplankton and benthic chlorophyll $a$ (Chl-a) to total biomass in the two treatments by the end of the experiment. 


\section{Discussion}

As expected, the artificial substrate significantly reduced nutrient concentrations (Figure 2) and the biomass of phytoplankton (Figure 4a) while water clarity increased (Figure 3a), as did the biomass of benthic algae (judged from changes in Chl-a) (Figure 4b). Artificial substrate may therefore pave the way for a benthic-dominated or in the longer term a macrophyte-dominated system via changes in water chemical-physical conditions.

We found significantly lower nitrogen and phosphorus concentrations in the mesocosms with artificial substrate than in the controls (Figure 2a,b). Similarly, Vymazal (1988), studying the nutrient removal efficiency of periphyton communities on nylon screens in polluted streams, found high maximum efficiencies of ammonium and orthophosphate removal ( $80 \%$ and $70 \%$, respectively) [14]. Also Adey et al. (1993), Dodds (2003), and Jöbgen et al. (2004) recorded that exposed artificial substrate in lakes or streams removed a large amount of phosphorus from the water column $[16,17,19]$. However, in our study, dissolved nutrient levels (TDN and TDP) did not differ significantly between the treatments (Figure 2c,d), possibly reflecting a rapid uptake of accessible inorganic nutrients by the primary producers in the mesocosms.

Artificial substrate also resulted in lower concentrations of particulate organic and inorganic particles and thereby improved the water clarity (Figure 3a). Others, for example Sansone et al. (1998), Battin et al. (2003), and Salant et al. (2011), have shown that periphyton captured or trapped fine particles by modifying shear stress and surface adhesion [20-22]. The lower OSS concentration (Figure 3c) in the artificial substrate mesocosms may in part reflect a lower phytoplankton biomass (Figure 4a). Moreover, we also calculated non-algal organic suspended solids by subtracting the contribution of phytoplankton to OSS (using a conversion factor from Jeppesen et al., 2003 [28]). Furthermore, non-phytoplankton OSS was also significantly lower than in the controls (data not shown), indicating that artificial substrate also decreases the amount of other organic particles, such as detritus, in the water column. The observed decrease in inorganic particles (ISS) in the mesocosms with artificial substrate (Figure 3d) may be attributed to the adhesion effect [20] exerted by the periphyton canopy (Figure $4 b$ ). Supporting this view, in a study exploring the influence of streambed periphyton on particle deposition and infiltration using a series of flume experiments, all periphytic diatom surface samples were found to have significantly higher inorganic contents than non-periphyton surfaces [22].

We found a lower phytoplankton biomass in the mesocosms with artificial substrate (Figure 4a) than in the controls, likely reflecting the reduced nutrient concentrations (Figure 2). Concurrently with the subsequently lower turbidity in these mesocosms, Chl- $a$ in the sediment was higher and the share of algae in the sediment substantially higher than in the controls (Figure $4 \mathrm{~b}$ ). By being able to take up nutrients from sediments, benthic algae are favored when water clarity is high [3,8]. However, we cannot exclude that part of the higher Chl- $a$ in the sediment in the mesocosms with artificial substrate derived from settling of periphytic material. Such material, when continuing growth on the sediment, is expected to reduce also the phosphorus release from the sediment as well as phytoplankton growth.

Our study has limitations. Firstly, the experimental period only covered one season-the autumn. The growth rate for phytoplankton in this season may be lower than in summer. However, in subtropical Lake Taihu, previous studies have shown phytoplankton to grow actively in October [29]. Secondly, we did not add nutrients during the experiment period, which resulted in significant declines in TN and TDN (Figure 1). Nonetheless, the final TN and TDN concentrations in the treatment with artificial substrate were 0.88 and $0.70 \mathrm{mg} \cdot \mathrm{L}^{-1}$, respectively. The high TDN levels, moreover, indicate that the decreased growth of phytoplankton in the mesocosms with artificial substrate was not caused by insufficient $\mathrm{N}$ for growth. Finally, our experiment was of short-term duration, covering a build-up phase of periphyton. Whether the effect will be maintained if the artificial substrate be exposed for longer time is unclear and warrants further studies.

Measures taken to restore shallow eutrophic lakes frequently involve attempts to re-establish benthic primary producers, especially submerged vegetation $[1,30]$. Prior to such restoration, improvement of water physical-chemical conditions, for instance light $(+)$ and nutrient levels $(-)$, is 
recommended. Our study revealed that exposed artificial substrate in eutrophic waters significantly reduced nutrient levels and enhanced water clarity in the water column. These changes led to enhanced benthic algae growth and reduced phytoplankton biomass. Additionally, artificial substrate exposed in eutrophic waters may also have other effects reinforcing a shift to the clear-water state. For instance, studies from temperate lakes have shown artificial plant beds to act as a daytime refuge for large-bodied zooplankton [31]. Other studies have demonstrated that artificial plants substantially increased macroinvertebrate food resources for piscivorous fish, for instance perch (Perca fluviatilis L.) [32,33]. Thus, when combining the results of these studies with ours, we conclude that introduction of artificial substrate may be a valuable restoration tool in shallow eutrophic lakes after an external nutrient loading reduction in order to speed up recovery and the establishment of natural submerged macrophyte beds. However, the small scale and short duration of our experiment obviously prevent a direct transfer of our results to the whole-lake level. Thus, large-scale and long-term experiments are required before any firm conclusions can be drawn about the usefulness of artificial substrate as a lake restoration method.

Acknowledgments: The authors wish to express their gratitude to Xiaoxia Chen and Ruijie Shen for field and laboratory support and to Anne Mette Poulsen for language assistance. This study was supported by the National Science Foundation of China (31500379, 31370477 and 41571086), by the MARS project (Managing Aquatic ecosystems and water Resources under multiple Stress) funded under the 7th EU Framework Programme, Theme 6 (Environment including Climate Change), Contract No. 603378 (http://www.mars-project.eu), and CLEAR (a Villum Kann Rasmussen Centre of Excellence project).

Author Contributions: $\mathrm{Hu} \mathrm{He}$, Xuguang Luo and Kuanyi Li designed the study, Hu He, Jiao Gu and Hui Jin undertook the sampling, Hu He, Erik Jeppesen, Kuanyi Li and Zhengwen Liu conducted the data analyses and wrote the paper.

Conflicts of Interest: The authors declare no conflict of interest.

\section{References}

1. Scheffer, M.; Hosper, S.H.; Meijer, M.L.; Moss, B.; Jeppesen, E. Alternative equilibria in shallow lakes. Trends Ecol. Evol. 1993, 8, 275-279. [CrossRef]

2. Vadeboncoeur, Y.; Lodge, D.M.; Carpenter, S.R. Whole-lake fertilization effects on distribution of primary production between benthic and pelagic habitats. Ecology 2001, 82, 1065-1077. [CrossRef]

3. Liboriussen, L.; Jeppesen, E. Temporal dynamics in epipelic, pelagic and epiphytic algal production in a clear and a turbid shallow lake. Freshw. Biol. 2003, 48, 418-431. [CrossRef]

4. Genkai-Kato, M.; Vadeboncoeur, Y.; Liboriussen, L.; Jeppesen, E. Benthic-planktonic coupling, regime shifts, and whole-lake primary production in shallow lakes. Ecology 2012, 93, 619-631. [CrossRef] [PubMed]

5. Hansson, L.A. Effects of competitive interactions on the biomass development of planktonic and periphytic algae in lakes. Limnol. Oceanogr. 1988, 33, 121-128. [CrossRef]

6. Sand-Jensen, K.; Borum, J. Interactions among phytoplankton, periphyton, and macrophytes in temperate freshwaters and estuaries. Aquat. Bot. 1991, 41, 137-175. [CrossRef]

7. Vadeboncoeur, Y.; Steinman, A.D. Periphyton function in lake ecosystems. Sci. World J. 2002, 2, 1449-1468. [CrossRef] [PubMed]

8. Jäger, C.G.; Diehl, S. Resource competition across habitat boundaries: Asymmetric interactions between benthic and pelagic producers. Ecol. Monogr. 2014, 84, 287-302. [CrossRef]

9. Zhang, X.; Mei, X.; Gulati, R.D.; Liu, Z. Effects of N and P enrichment on competition between phytoplankton and benthic algae in shallow lakes: A mesocosm study. Environ. Sci. Pollut. Res. 2015, 22, 4418-4424. [CrossRef] [PubMed]

10. Zhang, X.; Liu, Z.; Gulati, R.D.; Jeppesen, E. The effect of benthic algae on phosphorus exchange between sediment and overlying water in shallow lakes: A microcosm study using 32P as a tracer. Hydrobiologia 2013, 710, 109-116. [CrossRef]

11. Søndergaard, M.; Jeppesen, E.; Lauridsen, T.L.; Skov, C.; Van Nes, E.H.; Roijackers, R.; Portielje, R.O.B. Lake restoration: Successes, failures and long-term effects. J. Appl. Ecol. 2007, 44, 1095-1105. [CrossRef]

12. Søndergaard, M.; Bjerring, R.; Jeppesen, E. Persistent internal phosphorus loading during summer in shallow eutrophic lakes. Hydrobiologia 2013, 710, 95-107. [CrossRef] 
13. Chen, F.; Shu, T.; Jeppesen, E.; Liu, Z.; Chen, Y. Restoration of a subtropical eutrophic shallow lake in China: Effects on nutrient concentrations and biological communities. Hydrobiologia 2013, 718, 59-71. [CrossRef]

14. Vymazal, J. The use of periphyton communities for nutrient removal from polluted streams. Hydrobiologia 1988, 166, 225-237. [CrossRef]

15. Pei, G.; Wang, Q.; Liu, G. The role of periphyton in phosphorus retention in shallow lakes with different trophic status, China. Aquat. Bot. 2015, 125, 17-22. [CrossRef]

16. Adey, W.; Luckett, C.; Jensen, K. Phosphorus removal from natural waters using controlled algal production. Restor. Ecol. 1993, 1, 29-39. [CrossRef]

17. Dodds, W.K. The role of periphyton in phosphorus retention in shallow freshwater aquatic systems. J. Phycol. 2003, 39, 840-849. [CrossRef]

18. Hansson, L.A. Quantifying the impact of periphytic algae on nutrient availability for phytoplankton. Freshw. Biol. 1990, 24, 265-273. [CrossRef]

19. Jöbgen, A.; Palm, A.; Melkonian, M. Phosphorus removal from eutrophic lakes using periphyton on submerged artificial substrate. Hydrobiologia 2004, 528, 123-142. [CrossRef]

20. Sansone, U.; Belli, M.; Riccardi, M.; Alonzi, A.; Jeran, Z.; Radojko, J.; Cavolo, F. Adhesion of water-borne particulates on freshwater biota. Sci. Total Environ. 1998, 219, 21-28. [CrossRef]

21. Battin, T.J.; Kaplan, L.A.; Newbold, J.D.; Hansen, C.M. Contributions of microbial biofilms to ecosystem processes in stream mesocosms. Nature 2003, 426, 439-442. [CrossRef] [PubMed]

22. Salant, N.L. 'Sticky business': The influence of streambed periphyton on particle deposition and infiltration. Geomorphology 2011, 126, 350-363. [CrossRef]

23. Jones, J.I.; Duerdoth, C.P.; Collins, A.L.; Naden, P.S.; Sear, D.A. Interactions between diatoms and fine sediment. Hydrol. Process. 2014, 28, 1226-1237. [CrossRef]

24. Qin, B.Q.; Xu, P.Z.; Wu, Q.L.; Luo, L.C.; Zhang, Y.L. Environmental issues of lake Taihu, China. Hydrobiologia 2007, 581, 3-14. [CrossRef]

25. Ning, X.Y.; Gu, J.; Tan, B.C.; Zhu, X.L.; Li, K.Y. Effects of artificial substrate materials on eutrophic water quality improvement. Shanghai Environ. Sci. 2015, 34, 231-234. (In Chinese)

26. Jin, X.C.; Tu, Q.Y. The Standard Methods for Observation and Analysis in Lake Eutrophication, 2nd ed.; Environmental Science Press: Beijing, China, 1990. (In Chinese)

27. State Environmental Protection Administration (SEPA). Monitoring and Analytical Methods for Water and Wastewater, 4th ed.; Chinese Environmental Science Press: Beijing, China, 2002. (In Chinese)

28. Jeppesen, E.; Jensen, J.P.; Søndergaard, M.; Hansen, K.S.; Møller, P.H.; Rasmussen, H.U.; Larsen, S.E. Does resuspension prevent a shift to a clear state in shallow lakes during reoligotrophication? Limnol. Oceanogr. 2003, 48, 1913-1919. [CrossRef]

29. Paerl, H.W.; Xu, H.; McCarthy, M.J.; Zhu, G.W.; Qin, B.Q.; Li, Y.P.; Gardner, W.S. Controlling harmful cyanobacterial blooms in a hyper-eutrophic lake (Lake Taihu, China): The need for a dual nutrient (N \& P) management strategy. Water Res. 2011, 45, 1973-1983. [PubMed]

30. Gulati, R.D.; Pires, L.M.D.; Van Donk, E. Lake restoration studies: Failures, bottlenecks and prospects of new ecotechnological measures. Limnologica 2008, 38, 233-247. [CrossRef]

31. Schou, M.O.; Risholt, C.; Lauridsen, T.L.; Søndergaard, M.; Grønkjær, P.; Jacobsen, L.; Berg, S.; Skov, C.; Brucet, S.; Jeppesen, E. Restoring lakes by using artificial plant beds: Habitat selection of zooplankton in a clear and a turbid shallow lake. Freshw. Biol. 2009, 54, 1520-1521. [CrossRef]

32. Boll, T.; Balayla, D.; Andersen, F.Ø.; Jeppesen, E. Can artificial plant beds be used to enhance macroinvertebrate food resources for perch (Perca fluviatilis L.) during the initial phase of lake restoration by cyprinid removal? Hydrobiologia 2012, 679, 175-186. [CrossRef]

33. Balayla, D.; Boll, T.; Trochine, C.; Jeppesen, E. Does artificial plant beds facilitate microcrustacean development during biomanipulation of eutrophic shallow lakes? Hydrobiologia 2017, in revision.

(C) 2017 by the authors; licensee MDPI, Basel, Switzerland. This article is an open access article distributed under the terms and conditions of the Creative Commons Attribution (CC-BY) license (http://creativecommons.org/licenses/by/4.0/). 